Note

\title{
Antibacterial Activities of Surfactants in the Laundry Detergents and Isolation of the Surfactant Resistant Aquatic Bacteria
}

\author{
YOKO MAEHARA, AND SHIN-ICHI MIYOSHI* \\ Graduate School of Medicine, Dentistry and Pharmaceutical Sciences, Okayama University, \\ 1-1-1 Tsushima-Naka, Kita-Ku, Okayama-City, Okayama 700-8530, Japan \\ Received 3 March, 2017/Accepted 18 May, 2017
}

\begin{abstract}
Linear alkylbenzene sulfonate (LAS) and polyoxyethylene lauryl ether (POLE) are major surfactants contained in the laundry detergents. In the present study, the antibacterial activities of the surfactants to aquatic microorganisms were compared. When freshwater samples from a small river in Okayama city were treated with each of the surfactants, only LAS showed the significant antibacterial activity. Several strains, which survived after the treatment with $2.0 \%$ LAS, were isolated and identified by sequencing of $16 \mathrm{~S}$ rDNA. All strains were classified into the family Enterobacteriaceae. However, this family was not a major member of the aquatic microflora, suggesting that the bacteria in Enterobacteriaceae have a common property of LAS-resistance in the river water.
\end{abstract}

Key words : Surfactant / Laundry detergent / Linear alkylbenzene sulfonate / Aquatic bacteria.

The clothes and beddings are contaminated with many kinds of microorganisms derived from human skin as well as from environmental materials such as water, soil or animals. The surfactants in laundry detergents are known to function as antimicrobial agents against various microbes (Munk et al., 2001; Honisch et al., 2016), but the microorganisms resistant to the killing action of the surfactants have been isolated (Maeda et al., 1996; Munk et al., 2001). Therefore, attachment of the surfactant-resistant bacteria, especially human pathogenic ones, to clothes or beddings may increase the risk of infectious diseases. The bacteria in the families of Aeromonadaceae, Enterobacteriaceae and Vibrionaceae are common members of the microflora of various aquatic environments (Chowdhury et al., 1990, Shinoda et al., 2013). Most species in these families are nonpathogenic; however, several species are well known to be human pathogens.

Linear alkylbenzene sulfonate (LAS, anionic surfactant) and polyoxyethylen lauryl ether (POLE, nonionic surfactant) are major surfactants contained in laundry detergents. In the present study, antibacterial actions of

*Corresponding author. Tel / Fax: +81-86-251-7966, E-mail : miyos-s (a) okayama-u.ac.jp the surfactants to aquatic microbes were examined. Additionally, the surfactant-resistant aquatic bacteria were isolated and identified.

LAS $(\mathrm{C}=12-14)$ and POLE $\left(\mathrm{C}_{12} \mathrm{EO}_{23}\right)$ were purchased from Wako Pure Chemical Industries (Osaka, Japan). These surfactants were dissolved in purified water and followed by filter sterilization. The freshwater samples were collected from a small river in the afternoon of a fine day in late June. The river is near Okayama University campus and flows through a residential area. However, water pollution and influx of sewage was not observed around the sampling point. An aliquot of the sample $(0.5 \mathrm{~mL})$ was mixed with LAS or POLE (1.0 $\mathrm{mL}), 0.2 \%$ peptone broth $(5.0 \mathrm{~mL})$ prepared with 20 $\mathrm{mM}$ phosphate buffer ( $\mathrm{pH}$ 7.0), and purified water (3.5 $\mathrm{mL})$. Thereafter, each admixture $(10 \mathrm{~mL}$ ) was cultivated at $25^{\circ} \mathrm{C}$ with shaking, and the growth of aquatic microorganisms was periodically measured by monitoring increase in absorbance at $600 \mathrm{~nm}$.

By the addition of LAS (0 to $2.0 \%$ ), the microbial growth was reduced, and the lag period was extended in a dose-dependent manner. However, the significant growth was observed even in the presence of 2.0\% LAS (Fig.1A). These findings indicate that, although LAS has significant bactericidal and/or bacteriostatic 


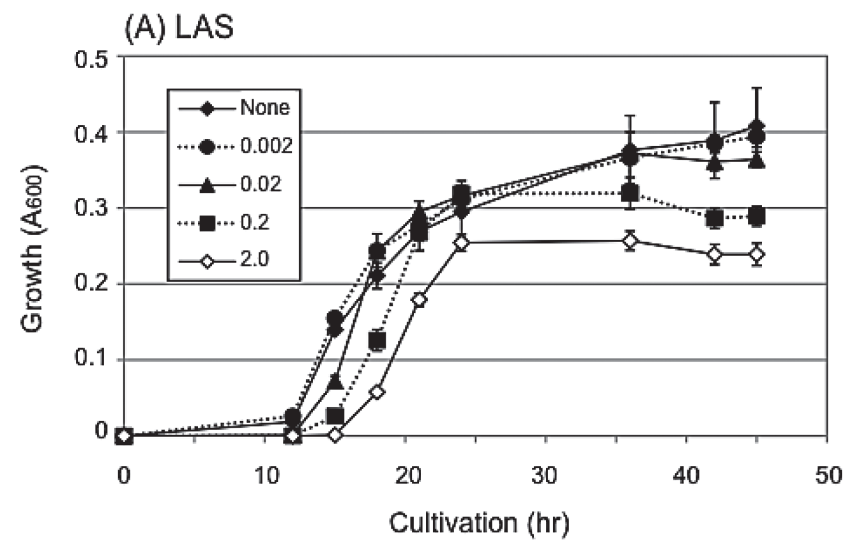

(B) POLE

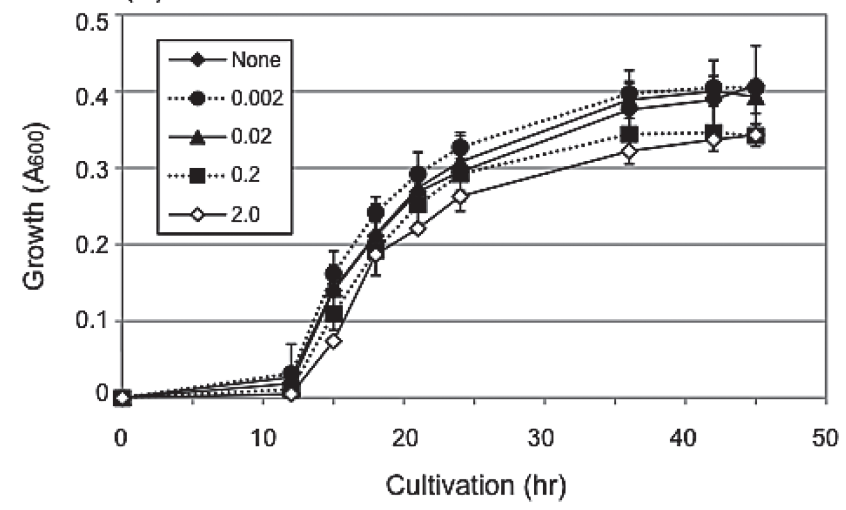

FIG. 1. Effects of surfactants on the growth of aquatic microorganisms. The freshwater sample was mixed with $0-2.0 \%$ LAS (A) or POLE (B) in $0.1 \%$ peptone broth. Thereafter, each mixture was cultivated at $25^{\circ} \mathrm{C}$ with shaking, and the growth of aquatic microorganisms $\left(A_{600}\right)$ was measured periodically $(n=$ 3).

activity, LAS-resistant bacteria are present in the freshwater samples. In contrast, POLE showed negligible effect on the growth of aquatic microorganisms (Fig.1B), indicating POLE has far less antimicrobial activity.

For qualitative analysis of the LAS-resistant aquatic bacteria, the freshwater sample cultivated at $25^{\circ} \mathrm{C}$ for 2 days in $0.1 \%$ peptone broth containing $2.0 \%$ LAS was diluted $10^{5}$-fold with sterilized PBS $(10 \mathrm{mM}$ phosphate buffer containing $0.8 \% \mathrm{NaCl}, \mathrm{pH} 7.0$ ), and the diluted culture was inoculated on nutrient agar plates (Nissui Pharmaceutical, Tokyo). After cultivation at $25^{\circ} \mathrm{C}$ for 2 days, several representative colonies of which size, color and surface properties were different each other were picked up.

Next, to identify the bacterium isolated, 16S rDNA was amplified by PCR (Weisbeurg et al., 1991). Namely, the genomic DNA was prepared by using the Illustra bacteria genomicPrep Mini Spin Kit (GE Healthcare, Buckinghamshire, UK) and an aliquot of the DNA preparation (50 ng) was mixed with the primer set, $27 \mathrm{~F}$
TABLE 1. PCR primers used for amplification of $16 S$ rDNA

\begin{tabular}{ll}
\hline Primer & \multicolumn{1}{c}{ Sequence } \\
\hline $27 F$ & 5'-AGAGTTGATCCTGGCTCAG-3' \\
$520 F$ & 5'-GTGCCAGCAGCCGCGG-3' \\
520R & 5'-ACCGCGGCTGCTGGC-3' \\
920R & 5'-CCGTCAATCCTTGAGTT-3' \\
$1100 F$ & 5'-GCAACGAGCGCAACCC-3' \\
1492R & 5'-GGTACCTTGTTACGACTT-3' \\
\hline
\end{tabular}

(20 pmol) and $1492 \mathrm{R}$ (20 pmol) (Table 1), and Go Taq Green Master Mix (25 $\mu \mathrm{L})$ (Promega, Fitchburg, Wisconsin, USA), and then, purified water was added up to $50 \mu \mathrm{L}$. The reaction mixture thus prepared was set on a thermal cycler and was heat-treated at $94^{\circ} \mathrm{C}$ for 3 min. Thereafter, the 30-cycle amplification reaction was performed with following conditions, denaturation at $94^{\circ} \mathrm{C}$ for $30 \mathrm{sec}$, annealing at $47^{\circ} \mathrm{C}$ for $30 \mathrm{sec}$, and extension at $72^{\circ} \mathrm{C}$ for $90 \mathrm{sec}$.

After PCR, the product was subjected to agarose gel electrophoresis, and the target amplicon was extracted by using FastGene Gel/PCR Extraction Kit (Nippon Genetics, Tokyo). The extracted amplicon (30 ng) was mixed with each of the primers $(6.6 \mathrm{pmol})$ shown in Table 1 (forward primer: $27 \mathrm{~F}, 520 \mathrm{~F}$ or $1100 \mathrm{~F}$, reverse primer: 520 R, 920 R or 1492 R), ABI PRISM BigDye Terminator v1.1 Cycle Sequencing Kit (Thermo Fisher Scientific, Waltham, Massachusetts, USA) (1.0 $\mu \mathrm{L})$, and 5 -fold concentrated Dilution Buffer $(7.5 \mu \mathrm{L})$, and then, purified water was added up to $40 \mu \mathrm{L}$. Thereafter, the reaction mixture was subjected to the 25 -cycle PCR amplification (denaturation at $96^{\circ} \mathrm{C}$ for $10 \mathrm{sec}$, annealing at $50^{\circ} \mathrm{C}$ for $5 \mathrm{sec}$, and extension at $60^{\circ} \mathrm{C}$ for $4 \mathrm{~min}$ ). Subsequently, the PCR product was purified and dissolved in $20 \mu \mathrm{L}$ of Hi-di (Thermo Fisher Scientific). After heat treatment at $96^{\circ} \mathrm{C}$ for 2 min, the nucleotide sequence of each amplicon was determined with $A B I$ PRISM 3130-Avant Genetic Analyzer (Thermo Fisher Scientific). For identification of the bacterial species, the resultant sequence of $16 S$ rDNA was compared with those of bacteria listed on the database Basic Local Alignment Search Tool (BLAST) (https://blast.ncbi.nlm. nih.gov/Blast.cgi), and the sequence of which homology was $99.0 \%$ or higher was searched (Stacebrandt and Goebel, 1994; Janda and Abbott, 2007).

A total of 6 strains (LS01 to LS06) were isolated as the LAS-resistant bacteria, which could grow in the presence of 2.0\% LAS. As shown in Table 2, all of the strains were classified into the genus in Enterobacteriaceae. That is, 4 strains were Enterobacter, 1 strain was Pantoea, and 1 strain was Raoultella. Except for strain LSO3, the bacteria isolated were identified at the species level. The 
TABLE 2. Bacterial strains which could grow in the presence of $2.0 \%$ LAS

\begin{tabular}{llcc}
\hline Strain & \multicolumn{1}{c}{ Closest relative } & Accession number & Homology (\%) \\
\hline LS01 & Enterobacter cloacae subsp. dissolvens & GU191924 & 100.0 \\
LS02 & Pantoea agglomerans & AM182490 & 99.9 \\
LS03 & Enterobacter species & FN433019 & 100.0 \\
LS04 & Raoultella ornithinolytica & HQ259705 & 100.0 \\
LS05 & Enterobacter asburiae & EU221358 & 99.9 \\
LS06 & Enterobacter asburiae & EU221358 & 99.9 \\
\hline
\end{tabular}

Enterobacteriaceae contains several human pathogens. However, any strain was not positioned to this category, which suggests no pathogenic bacterium was selected specifically by the addition of LAS to the cultivation broth.

In order to examine the bactericidal actions of the surfactants on aquatic bacteria, the freshwater sample (0.5 mL) was mixed with $0-20 \%$ LAS or POLE (0.1 $\mathrm{mL}$ ) and $0.25 \%$ peptone broth $(0.4 \mathrm{~mL})$, and each admixture was incubated at $25^{\circ} \mathrm{C}$ for 30 min with shaking. Thereafter, the numbers of the living bacterial cells (CFU) were measured by inoculation on nutrient agar plates. As shown in Fig.2, although POLE was found to have a little bactericidal activity, LAS showed the apparent activity to aquatic bacteria. The bactericidal activity was the dose-dependent but reached a plateau at $0.2 \%$ LAS.

The bacterial strains, which showed resistance to the killing action of LAS, were isolated from the samples treated with $2.0 \%$ LAS at $25^{\circ} \mathrm{C}$ for $30 \mathrm{~min}$. A total of 7 representative colonies (strain LSS01 to LSS07) were picked up and were identified by sequencing of 16S rDNA (Table 3). Only two strains (LSS03 and LSS04) were identified at the species level. However, as well as the former experiment (Table 2), all isolates were found to be the genus in Enterobacteriaceae, such as Klebsiella (3 strains), Enterobactor (2 strains), Citrobacter (1 strain) or Pantoea (1 strain). On the other hand, no strain isolated was categorized to be a human pathogen.

As mentioned above, a total of 13 strains were isolated as LAS-resistant aquatic bacteria, and they were classified into the family Enterobacteriaceae without exception. To investigate whether this family is a major bacterial group in the river water, the freshwater samples were inoculated on nutrient agar plates without the LAS-treatment. After cultivation at $25^{\circ} \mathrm{C}$ for 2 days, 18 representative colonies were picked up for the qualitative analysis of the river water microflora. Amongst them, 16 strains were in Pseudomonas (7 strains), Acinetobacter (6 strains), Acidovorax (1 strain), Aeromonas (1 strain) or Shewanella (1 strain), and 1 strain was closest to the uncultured bacterium clone L8. Namely, only 1 strain identified as Klebsiella oxytoca
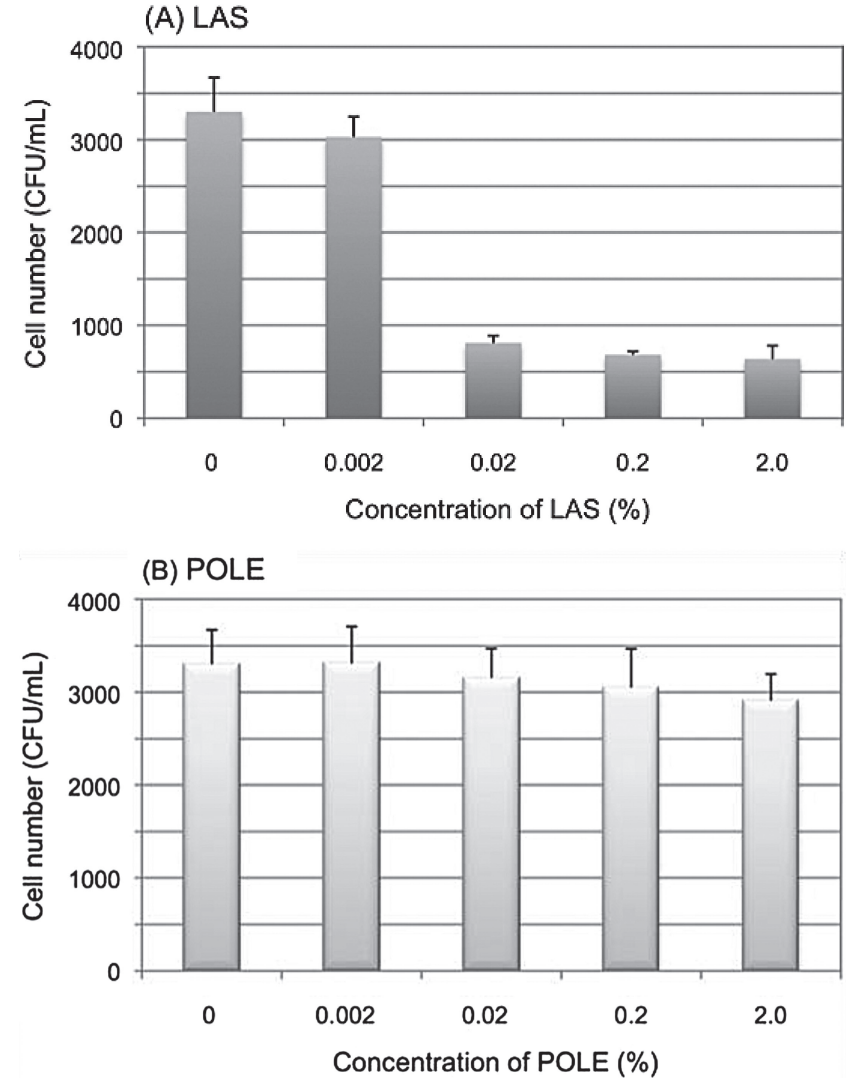

FIG. 2. Bactericidal activities of surfactants to aquatic bacteria. The freshwater sample was mixed with 0-2.0\% LAS or POLE in $0.1 \%$ peptone broth. Thereafter, each mixture was incubated at $25^{\circ} \mathrm{C}$ for 30 min with shaking, and the numbers of the living bacterial cells (CFU) were measured by inoculation on nutrient agar plates $(n=3)$.

was found to be in the family Enterobacteriaceae. Several researchers have carried out the quantitative analysis of aquatic microflora, and they have documented that Enterobacteriaceae is not a popular member (McLellan et al., 2015; Lu et al., 2016; Feng et al., 2016). In addition, the bacteria in this family are generally used as indicators of fecal contamination. Taken together, it may be concluded that the LAS-treatment caused selective 
TABLE 3. Bacterial strains which were resistant to the killing action of $2.0 \%$ LAS

\begin{tabular}{clcc}
\hline Strain & \multicolumn{1}{c}{ Closest relative } & Accession number & Homology (\%) \\
\hline LSS01 & Klebsiella species (Uncultured clone) & DQ279306 & 99.1 \\
LSS02 & Enterobacter species & AB308444 & 99.7 \\
LSS03 & Klebsiella oxytoca & AB353048 & 99.1 \\
LSS04 & Citrobacter freundii & AF025365 & 99.7 \\
LSS05 & Enterobacter species & FJ189785 & 99.9 \\
LSS06 & Klebsiella species & DQ831003 & 99.5 \\
LSS07 & Pantoea species & GQ395336 & 99.5 \\
\hline
\end{tabular}

survival of bacteria in Enterobacteriaceae. It should be noted that several human pathogenic bacteria in Enterobacteriaceae have been reported to modify the osmotically controlled periplasmic glucans (OPG) to resist to anionic surfactants including LAS (Rajagopal et al., 2003; Bhagwat et al., 2012). Therefore, the ability to modify OPG may be an important property common to the LAS-resistant bacteria isolated.

In conclusions, an anionic surfactant LAS showed the significant bactericidal activity to aquatic bacteria, but the bacteria in the family Enterobacteriaceae were suggested to be commonly resistant to LAS. In addition, it was indicated the LAS-treatment might not result in specific selection of human pathogens habiting in freshwater, except for Enterobacteriaceae.

\section{ACKNOWLEDGMENTS}

This study was supported by a grant from the All Japan Laundry and Drycleaning Association.

\section{REFERENCES}

Bhagwat, A. A., Leow, Y. N., Liu, L, Dharne M., and Kannan, P. (2012) Role of anionic charges of periplasmic glucans of Shigella flexneri in overcoming detergent stress. Foodborne Pathog. Dis. 9 : 632-637.

Chowdhury, M. A. R., Yamanaka, H., Miyoshi, S., and Shinoda, S. (1990) Ecology of mesophilic Aeromonas spp. in aquatic environments of a temperate region and relationship with some biotic and abiotic environmental parameters. Zbl. Hyg. 190 : 344-356.

Feng, Q., Han, L., Tan, X., Zhang, Y., Meng, T., Lu, J., and LV J. (2016) Bacterial and archaeal diversities in Maotai section of the Chishui River, China. Curr. Microbiol. 73 : $924-$ 929.

Honisch, M., Brands, B., Weide, M., Speckmann, H. D., Stamminger, R., and Bockmul, D. (2016) Antimicrobial efficacy of laundry detergents with regard to time and temperature in domestic washing machines. Tenside Surfact. Det. 53 : 547-552.

Janda J. M., and Abbott, S. L. (2007) 16S rRNA gene sequencing for bacterial identification in the diagnostic laboratory: pluses, perils, and pitfalls. J Clin. Microbiol. 45 : 2761-2764.

Lu, S., Sun, Y., Zhao, X., Wang, L., Ding, A., and Zhao X. (2016) Sequencing insights into microbial communities in the water and sediments of Fenghe River, China. Arch. Environ. Contam. Toxicol. 71 : 122-132.

Maeda, T., Goto, S., Manabe, Y., Okazaki, K., Nagamune, H., and Kourai, H. (1996) Bactericidal action of $\mathrm{N}$ alkylcyanopyridinium bromide $\mathrm{A}$ against Escherichia coli K12W3110. Biocontrol Sci. 1: 41-49.

McLellan, S. L., Fisher, J. C., and Newton, R. J. (2015) The microbiome of urban waters. Int. Microbiol. 18 : 141-149.

Munk, S., Johansen, C., Stahnke, L. H., and Adler-Nissen, J. (2001) Microbial survival and odor in laundry. J. Surfactants Deterg. 4 : 385-394.

Rajagopal S., Eis, N., and Nickerson, K. W. (2003) Eight Gram-negative bacteria are 10000 times more sensitive to cationic detergents than to anionic detergents. Can. J. Microbiol. 49 : 775-779.

Shinoda, S., Furumai, Y., Katayama, S., Mizuno, T., and Miyoshi, S. (2013) Ecological study of pathogenic vibrios in aquatic environments. Biocontrol Sci. 18 : 53-58.

Stacebrandt E., and Goebel, B. M. (1994) Taxonomic note: a place for DNA-DNA reassociation and 16S rRNA sequence analysis in the present species definition in bacteriology. Int. J. System. Bacteriol. 44 : 846-849.

Weisburg, W. G., Barns, S. M, Pelletier, D. A., and Lane, D. J. (1991) 16S ribosomal DNA amplification for phylogenetic study. J. Bacteriol. 173 : 697-703. 